\title{
Long-term outcomes and prognostic analysis of modified open-door laminoplasty with lateral mass screw fusion in treatment of cervical spondylotic myelopathy
}

\author{
This article was published in the following Dove Press journal: \\ Therapeutics and Clinical Risk Management \\ 31 August 2016 \\ Number of times this article has been viewed
}

\author{
$\mathrm{Nan} \mathrm{Su}$ \\ Qi Fei \\ Bingqiang Wang \\ Dong Li \\ Jinjun Li \\ Hai Meng \\ Yong Yang \\ Ai Guo \\ Department of Orthopedics, Beijing \\ Friendship Hospital, Capital Medical \\ University, Xicheng District, Beijing, \\ People's Republic of China
}

Correspondence: Yong Yang; Ai Guo Department of Orthopedics, Beijing Friendship Hospital, Capital Medical University, No 95, Yong'an Road, Xicheng District 100050, Beijing, People's Republic of China Tel +861063138353

Fax +86 10 8391 1029

Email spineyang@126.com; guoaij@139.com
Objectives: The purpose of the present study was to explore and analyze the long-term outcomes and factors that affect the prognosis of expansive open-door laminoplasty with lateral mass screw fusion in treatment of cervical spondylotic myelopathy (CSM).

Methods: We retrospectively reviewed 49 patients with multilevel CSM who had undergone expansive open-door laminoplasty with lateral mass screws fixation and fusion in our hospital between February 2008 and February 2012. The average follow-up period was 4.6 years. The clinical data of patients, including age, sex, operation records, pre- and postoperation Japanese Orthopedic Association (JOA) scores, cervical spine canal stenosis, and cervical curvature, were collected. Increased signal intensity (ISI) on T2-weighted magnetic resonance imaging and ossification of the posterior longitudinal ligament were also observed. Paired $t$-test was used to analyze the treatment effectiveness and recovery of neuronal function. The prognostic factors were analyzed with multivariable linear regression model.

Results: Forty-nine patients with CSM with a mean age of 59.44 years were enrolled in this study. The average of preoperative JOA score was $9.14 \pm 2.25$, and postoperative JOA score was $15.31 \pm 1.73$. There was significant difference between the pre- and postoperative JOA scores. The clinical improvement rate was $80.27 \%$. On follow-up, five patients had complaints of neck and shoulder pain, but no evidence of C5 nerve palsy was found. Developmental cervical spine canal stenosis was present in all patients before surgery. Before surgery, ISI was observed in eight patients, while ossification of the posterior longitudinal ligament was found in 12 patients. The average of preoperative cervical curvature was $21.27^{\circ} \pm 8.37^{\circ}$ and postoperative cervical curvature was $20.09^{\circ} \pm 1.29^{\circ}$, and there was no significant difference between the pre- and postoperative cervical curvatures. Multivariable linear regression analysis results showed that the postoperation JOA scores were significantly affected by age, preoperative JOA scores, and preoperative ISI. Except one case of epidural hematoma, there were no complications associated with the surgery.

Conclusion: Treatment of CSM with posterior open-door laminoplasty with lateral mass screw fusion is effective with few complications. In addition, the normal cervical lordosis was well maintained. Age, preoperative JOA scores, and preoperative ISI were the independent factors that significantly affect disease prognosis and surgical outcomes.

Keywords: cervical spondylotic myelopathy, laminoplasty, lateral mass screw, prognostic factors, ossification of the posterior longitudinal ligament, JOA scores

\section{Introduction}

Cervical spine disease is a group of clinical syndromes commonly seen in the orthopedics clinic, which is caused by degeneration of cervical disk and the surrounding 
bone and soft tissues. There are many subtypes of cervical spine disease, among which cervical spondylotic myelopathy (CSM) is the most common one. CSM is a disease in which spondylotic changes lead to cervical cord injury, resulting in clinical deficits. In CSM patients, since the spinal cord is injured (usually caused by oppression), spastic paralysis of limbs is commonly seen, which may cause decreased flexibility of hands, unsteady gait, and imbalance. With the progress of the disease, limb numbness and bladder dysfunction may occur, which will cause disability and severely reduce the quality of life of patients. Therefore, CSM is the most detrimental type of cervical spine disease.

Once CSM is diagnosed, usually a surgical approach to relieve cervical spinal cord compression is needed. Surgical treatment can not only stop disease progression but also improve neurological function in patients to varying degrees. ${ }^{1}$ The surgical approach includes anterior surgery (cervical discectomy, cervical corpectomy, and anterior fixation and fusion), posterior surgery (mainly the so-called expansive open-door or double-door laminoplasty), and combined anterior and posterior surgery. The posterior surgery can not only remove the oppressor to the spinal cord, such as yellow ligaments, to relieve the compression directly, but also expand the volume of the spinal canal so that the cervical spinal cord is forced to drift backward to indirectly relieve the compression. Clinically, the posterior surgery is generally used in CSM patients with three or more spinal cord segments involved or with combination of developmental cervical spinal canal stenosis. However, due to the fact that the cervical spine is not been fixed and fused, the incidence rate of kyphotic deformity after posterior surgery is high; ${ }^{2}$ meanwhile, there is a possibility that the spinal lamina will be "reclosed". In order to overcome these complications, efforts have been made to modify posterior surgery, including the most commonly seen in the clinic, ie, posterior cervical expansive "open-door" laminoplasty with short-segment (C4-6) lateral mass screw fusion, which achieved satisfactory clinical outcomes. However, there are few long-term follow-up studies of such a modified operation to verify its efficacy and safety, and there is no report about the factors that affect its efficacy.

In the current study, we followed up CSM patients who underwent modified posterior surgery, ie, expansive opendoor laminoplasty with lateral mass screw fusion in our hospital between February 2008 and February 2012. Our goal is to study the mid- and long-term effects of the modified posterior surgery on CSM and the possible complications and to investigate the factors that affect its clinical efficacy in order to guide future clinical practice in this field.

\section{Materials and methods Demographic and clinical characteristics of the study subjects}

The study subjects were selected from a patient pool of 68 who were diagnosed with CSM with combination of developmental cervical spine canal stenosis and underwent modified posterior surgery, ie, expansive open-door laminoplasty with lateral mass screw fusion in our hospital between February 2008 and February 2012. All 68 patients were diagnosed with CSM after complete imaging studies. All of them had spinal cord injury symptoms, signs, and imaging findings, with two or more oppressed spinal cord segments, with concomitant developmental cervical spinal canal stenosis (the $\mathrm{C} 4$ spinal canal-to-vertebral body ratio was $<0.75$ ), without surgical contraindications, and without cervical tumor, trauma leading to cervical fracture, dislocation, or severe cervical kyphosis. After outpatient and telephone follow-up, 49 out of the 68 cases completed the full follow-up course, and the follow-up rate was $73.5 \%$. Of the 49 cases, 38 were males and 12 were females, with a mean age of $59.44 \pm 10.54$ years.

The inclusion criteria were patients 1) with a clear diagnosis of CSM with developmental cervical spinal canal stenosis; 2) older than 40 years; 3) who had undergone posterior cervical expansive open-door laminoplasty; and 4) who had a follow-up of $>3$ years.

The exclusion criteria were patients with 1) a previous history of cervical spine fracture, dislocation, or tumors; 2) comorbidity of neurological disorders leading to cervical spinal cord or pyramidal tract impairment; 3) incomplete imaging data; 4) the presence of severe preoperative cervical kyphosis (with kyphosis angle $>13^{\circ}$ ); and 5) the presence of severe preoperative osteoporosis.

All patients underwent routine preoperative preparations including imaging studies such as cervical spine anteroposterior and lateral flexion-extension X-ray, cervical computed tomography and cervical magnetic resonance imaging (MRI) examinations, and routine treatment of coexisting medical complications. All patients received cervical spine surgery and postoperative rehabilitation in the same hospital, and the same group of experienced doctors completed all the surgeries.

This study was approved by Beijing Friendship Hospital Ethics Committee, and all study subjects signed informed consent form to voluntarily participate in this study.

\section{Surgical approaches}

Under general anesthesia, the patient was placed in prone position to the operating table with the head stabilized with an ice-ring-like skull clamp. After routine disinfection, operation sheet and towel placement, and skin preparation, a posterior 
median longitudinal incision was made on the neck. The skin, subcutaneous tissue, and fascia were incised sequentially. Subperiosteal C3-7 spinous lamina muscle was isolated to expose the $\mathrm{C} 3-7$ spinous process, lamina, and the lateral side of bilateral C4-6 spine. A guide needle was inserted from the lateral side of C4-6, and a lateral side fixing hole was drilled for later use. The interspinous ligament of C2-3 and C7-T1 was incised, and the excessively long spinous process was also removed, with only $\sim 3 \mathrm{~mm}$ retained. A hole was drilled at the root of the $\mathrm{C} 3-7$ spinous process, and a size 10 silk thread was passed through the hole for hanging fixation later. The exterior cortex at the root of the right C3-7 lamina was drilled with an electric drill to make a door shaft with $\sim 0.3 \mathrm{~mm}$ wide. Then, the whole cortex layer at the root of the left C3-7 lamina was drilled through, and the left C3-7 yellow ligament was incised off, after the adhesions were carefully loosened. Then, the C3-7 laminal curtain was carefully lifted with a periosteal dissector, and the left side was left open to a range of $1.2-1.5 \mathrm{~cm}$. Three pairs of mass screws $(35 \times 12 \mathrm{~mm})$ were mounted on C4-6 side block bilaterally, the door shaft bone bed was rinsed, the nail bar was prebended, and the size 10 silk hanging thread mentioned earlier was placed below the right side of the shank; the screws were fixed one by one and eventually the nuts were locked tight. The removed C7 spinous process was cut into matchstick like and planted beside the door axle. Finally, the hanging thread was tied a knot in the nail bar. The wound was thoroughly washed, the inventory of gauze and instruments were cleared, an epidural hemostatic sponge was placed, a drainage tube was also placed, and finally the wound was closed layer by layer.

\section{Postoperative management}

The drainage tube was removed 48 hours after surgery. Antibiotics were used routinely for 2 days, methylprednisolone was used to reduce nerve root edema $(200 \mathrm{mg}, 80 \mathrm{mg}$, and $40 \mathrm{mg}$, oral daily for 2 days each sequentially), and lowmolecular-weight heparin was also used to prevent venous thrombosis. After the drainage tube was removed, the patient was asked to ambulate and exercise under the protection with neck brace; A/P X-ray was performed to check the recovery status of cervical spine.

\section{Data collection and analysis}

Through medical records, age, sex, course of hospitalization, operation time, blood loss, and perioperative complications for each patient were collected. All cases were followed up as outpatients, and preoperative and postoperative cervical spine Japanese Orthopedic Association (JOA) score (full score 17 points) and postoperative improvement rate were calculated: postoperative improvement rate $=($ follow-up JOA score - preoperative JOA score $) /(17$ - preoperative JOA score) $\times 100 \%$. Major residual symptoms at follow-up, C5 nerve root irritation situation, and restoration of social function were also recorded. Through analysis of lateral and $\mathrm{A} / \mathrm{P}$ $\mathrm{X}$-ray images before surgery and at follow-up, preoperative cervical spinal stenosis (ratio of lateral C4 spine canal sagittal diameter/vertebral body sagittal diameter) and cervical spine sagittal sequence (Cobb's angle that exists between lateral C2 vertebral end plates and C7 vertebral end plates) were measured. Internal fixation-related complications (screw displacement, fracture, and loosening) were also recorded through studying the cervical X-ray images at follow-up. The presence of increased signal intensity (ISI) on T2-weighted MRI and ossification of the posterior longitudinal ligament (OPLL) were also observed by studying preoperative MRI and computed tomography images.

\section{Statistical analysis}

SPSS 17.0 software was used for statistical analysis. All measurement data were presented as mean \pm standard deviation; qualitative data were expressed as percentage. Paired $t$-test was used to analyze pre- and postoperative JOA scores and cervical curvature. For comparison between two groups, $t$-test or Wilcoxon two sample test was used for measurement data and chi-square test or Fisher's exact test was used for qualitative data. Factors that affect postoperative improvement rate were analyzed with multivariate logistic regression.

\section{Results \\ General characteristics}

As shown in Table 1, among total 49 patients, 38 were males and 12 were females (one male patient died during followup, so the final sample size is 49), aged 37-79 years with a mean age of $59.44 \pm 10.54$ years. The mean operation time was $173.20 \pm 15.18$ minutes, the average amount of bleeding was $266.05 \pm 33.10 \mathrm{~mL}$, and the follow-up time was 36-84 months, with an average of 53.09 \pm 19.02 months. There was no case of perioperative anesthesia accident, cerebrovascular accident, wound infection, or wound nonhealing. One patient had epidural hematoma after surgery and still suffered from limb partial paraplegia (Frankel C grade) after evacuation of hematoma. One patient died of cerebrovascular disease during follow-up. All the remaining patients were able to return to normal daily routines.

\section{Results of neurological recovery}

The preoperative cervical JOAs of the 49 patients were $9.14 \pm 2.25$, postoperative JOAs were $15.31 \pm 1.73$, and the 
Table I General characteristic of the patients

\begin{tabular}{ll}
\hline Variants & Value, $\mathbf{N}=\mathbf{4 9}$ \\
\hline Sex, $\mathrm{n}(\%)$ & \\
$\mathrm{M}$ & $39(79.59)$ \\
$\mathrm{F}$ & $10(20.4 \mathrm{I})$ \\
Age (years), mean \pm SD & $59.45 \pm 10.17$ \\
Minimum & 36 \\
Maximum & 79 \\
Preop OPLL, $\mathrm{n}(\%)$ & \\
Yes & $20(40.82)$ \\
No & $29(59.18)$ \\
Segment, $\mathrm{n}(\%)$ & \\
$\mathrm{I}$ & $\mathrm{I}(2.04)$ \\
2 & $3(6.12)$ \\
3 & $30(61.22)$ \\
4 & $15(30.6 \mathrm{I})$ \\
ISI, $\mathrm{n}(\%)$ & \\
Yes & $23(46.94)$ \\
No & $26(53.06)$ \\
Ratio, ${ }^{\mathrm{a}}$ mean \pm SD & $0.628 \pm 0.034$ \\
Minimum & 0.57 \\
Maximum & 0.69 \\
Preop JOA, mean \pm SD & $9.93 \pm 2.29$ \\
Minimum & 4 \\
Maximum & 12 \\
Preop curvat, mean \pm SD & $19.85 \pm 6.79$ \\
Minimum & 6 \\
Maximum & 34 \\
Follow-up time (in months), mean \pm SD & $48.16 \pm 17.47$ \\
Minimum & 36 \\
Maximum & 84 \\
\hline
\end{tabular}

Note: aRatio of lateral C4 spine canal sagittal diameter and spine body sagittal diameter. Abbreviations: ISI, increased signal intensity; OPLL, ossification of the posterior longitudinal ligament; SD, standard deviation; JOA, Japanese Orthopedic Association; curvat, curvature.

difference was significant $(P<0.05)$. The average clinical improvement rate was $80.27 \%$. In terms of residual symptoms, there were 14 cases of residual numbness, seven cases of remaining upper limb dysfunction, especially hands, eleven cases with residual gait dysfunction (unsteady gait), and four patients still cannot ambulate and wheelchair was needed. At follow-up, five patients complained of neck and shoulder pain (incidence rate of $10.0 \%$ ), two of them with severe neck pain with visual analog score 7 . There was no C5 nerve palsy case. Three patients were not satisfied with the outcomes of surgery, one of them was complicated with postoperative epidural hematoma, and the two other cases were with severe pain in the shoulder and neck, as summarized in Table 2.

\section{Imaging analysis}

Developmental cervical canal stenosis was present in all 49 patients before surgery as shown with X-ray imaging, the ratio of lateral $\mathrm{C} 4$ canal sagittal diameter/vertebral body sagittal diameter was $0.62 \pm 0.03$. Analysis of preoperative
Table 2 Postoperative findings

\begin{tabular}{ll}
\hline Variants & Value, $\mathbf{N}=\mathbf{4 9}$ \\
\hline Postop JOA, mean \pm SD & $15.59 \pm 1.63^{\mathrm{a}}$ \\
Minimum & $1 \mathrm{I}$ \\
Maximum & 17 \\
Improvement rate, mean \pm SD & $83.78 \pm 18.0 \mathrm{I}$ \\
Minimum & 33.3 \\
Maximum & 100 \\
Residual symptoms, $\mathrm{n}(\%)$ & \\
None & $19(38.78)$ \\
Upper limb numbness & $15(30.6 \mathrm{I})$ \\
Lower limb instability & $13(26.53)^{\mathrm{b}}$ \\
Lower limb numbness & $5(10.20)$ \\
Postop curvat, mean \pm SD & $20.08 \pm 6.07 \mathrm{c}$ \\
Minimum & 10 \\
Maximum & 32 \\
Postop pain scale, VAS, $\mathrm{n}(\%)$ & \\
0 & $42(85.7 \mathrm{I})$ \\
2 & $4(8.16)$ \\
4 & $2(4.08)$ \\
8 & $1(2.04)$ \\
\hline
\end{tabular}

Notes: a Compared with that of preoperative, $P<0.05$. ${ }^{\text {T}}$ Two patients were wheelchair bound. 'Compared with that of preoperative, $P>0.05$.

Abbreviations: JOA, Japanese Orthopedic Association; curvat, curvature; VAS, visual analog scale; SD, standard devation.

MRI showed that eight cases had lesions in four spine segments, 34 cases had lesions in three segments, and eight cases had lesions in two segments. Before surgery, ISI was observed in T2-weighted images in eight patients (incidence rate $16 \%$ ), while OPLL was found in 12 patients (incidence rate $24 \%$ ). The average of preoperation cervical curvature (C2-7 Cobb's angle) was $21.27^{\circ} \pm 8.37^{\circ}$, postoperation cervical curvature was $20.09^{\circ} \pm 1.29^{\circ}$, and there was no significant difference between the pre- and postoperation cervical curvature $(P>0.05)$. All patients achieved bony fusion without pseudarthrosis formation. There was no loose, shift, break, pullout, poor location, or other complications for all internal fixation screws. The cervical X-ray and MRI images of a 61-year-old female representative patient with a follow-up time of 48 months are shown in Figures 1 and 2. The preoperative JOA score was 12, postoperative JOA score was 17 , and the patient was well recovered. Figures 1 and 2 show that the spinal cord in the preoperative image was compressed to "bead-like" shape, while postoperatively the compression was almost completely removed.

\section{Analysis of factors affecting postoperative JOA scores}

Multivariate logistic regression analysis was used to assess factors that may affect postoperative JOA scores, such as age, sex, cervical spine stenosis, preoperative and postoperative sagittal cervical curvature, and the presence of OPLL 
A

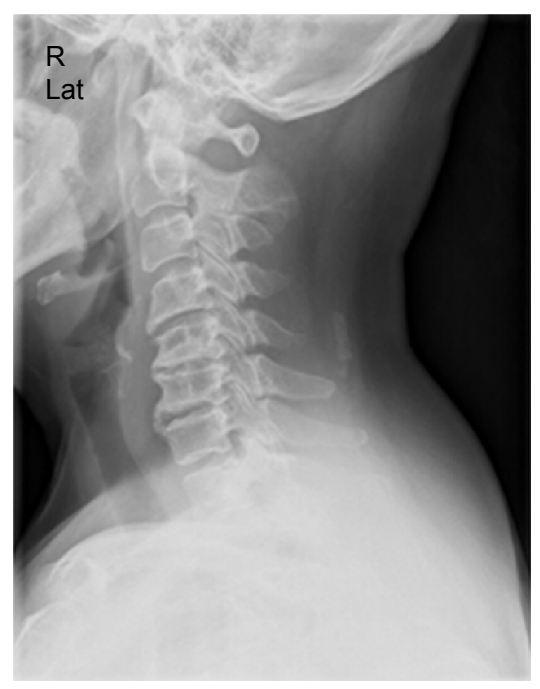

C

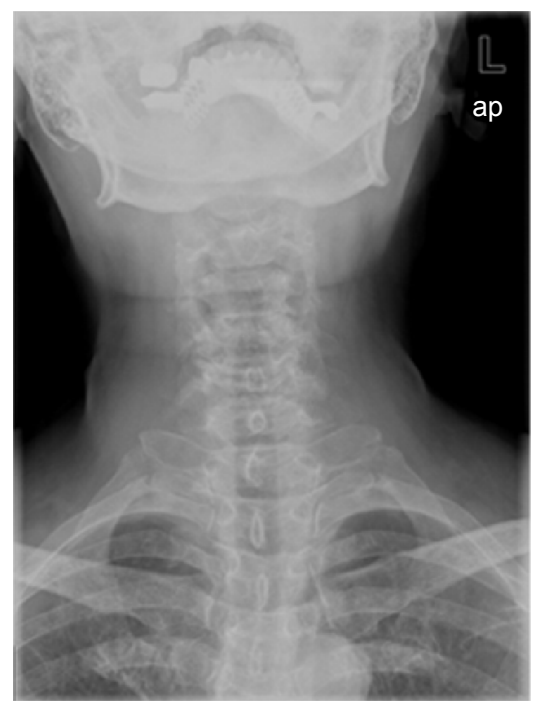

B

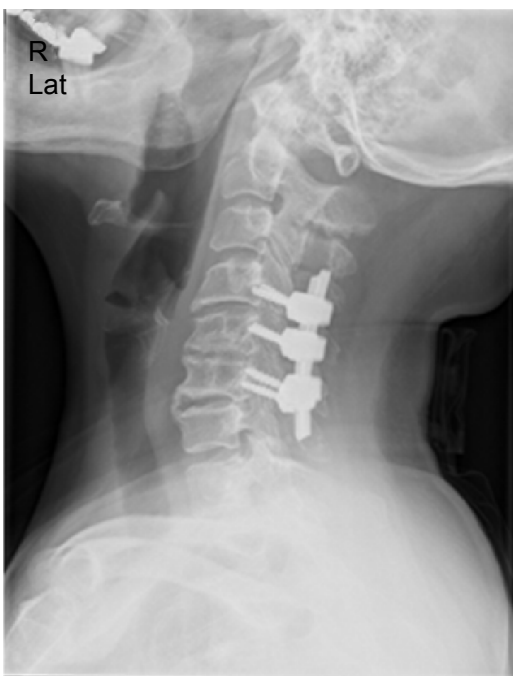

D

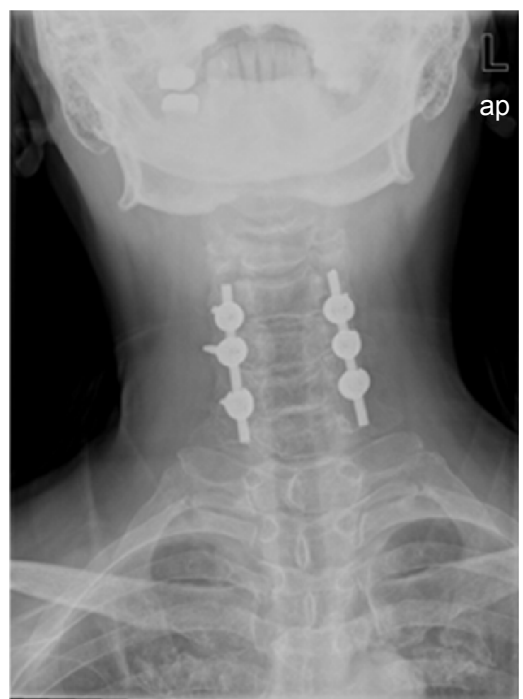

Figure I Preoperative and postoperative cervical X-ray images.

Notes: $(\mathbf{A})$ Preoperative right lateral $\mathrm{X}$-ray image, $(\mathbf{B})$ postoperative right lateral $\mathrm{X}$-ray image, $(\mathbf{C})$ preoperative left $A / P \mathrm{X}$-ray image, and $(\mathbf{D})$ postoperative left $A / P$-ray image.

Abbreviation: A/P, anterior/posterior.
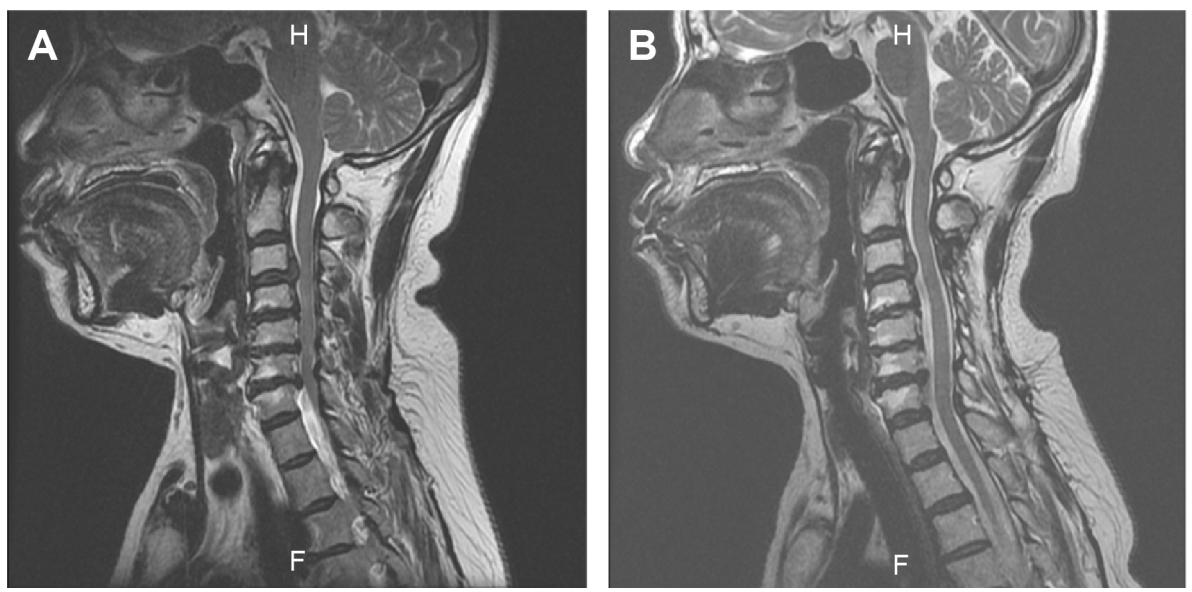

Figure 2 Preoperative and postoperative cervical MRI images.

Notes: (A) Preoperative MRI image showing the cord was compressed with "bead-like" shape. (B) Postoperative MRI image showing the compression of the cord was almost completely removed.

Abbreviation: MRI, magnetic resonance imaging. 
Table 3 Analysis of factors affecting postoperative JOA scores

\begin{tabular}{|c|c|c|c|c|c|c|}
\hline \multirow[t]{2}{*}{ Model } & \multirow[t]{2}{*}{ Variants } & \multicolumn{2}{|c|}{$\begin{array}{l}\text { Unstandardized } \\
\text { coefficients }\end{array}$} & \multirow[t]{2}{*}{$\begin{array}{l}\text { Standardized } \\
\text { coefficients, } \beta\end{array}$} & \multirow[t]{2}{*}{$t$-value } & \multirow[t]{2}{*}{$P$-value } \\
\hline & & $\beta$ & SE & & & \\
\hline \multirow[t]{10}{*}{$\mathrm{I}$} & Constant & -0.855 & 8.334 & & -0.103 & 0.920 \\
\hline & Sex & 0.005 & 0.727 & 0.001 & 0.007 & 0.994 \\
\hline & Cobb2 & 0.168 & 0.124 & 0.557 & 1.352 & 0.201 \\
\hline & Cobbl & -0.150 & 0.099 & -0.690 & -1.513 & 0.156 \\
\hline & JOAI & 1.008 & 0.215 & 1.162 & 4.681 & 0.001 \\
\hline & Segments involved & -1.062 & 0.579 & -0.400 & -1.836 & 0.091 \\
\hline & OPLL & 1.488 & 0.707 & -0.413 & 2.106 & 0.057 \\
\hline & $|S|$ & -2.523 & 0.883 & -0.685 & -2.859 & 0.014 \\
\hline & Ratio & 4.844 & 11.157 & 0.090 & 0.434 & 0.672 \\
\hline & Age & 0.111 & 0.046 & 0.699 & 2.405 & 0.033 \\
\hline
\end{tabular}

Abbreviations: JOA, Japanese Orthopedic Association; SE, standard error; OPLL, ossification of the posterior longitudinal ligament; ISI, increased signal intensity.

or ISI. As shown in Table 3, age, preoperative JOA score $(P<0.05)$, and the presence of cervical ISI were independent factors that significantly affected postoperative JOA scores $(P<0.05$ for all).

\section{Discussion}

CSM refers to the disease of spinal cord dysfunction caused by insufficient blood supply, which is usually the result of stimulation or compression from static factors such as herniated disk or osteophytes, or dynamic factors such as neck hypermobility or instability. In the literature, ${ }^{3} 40 \%$ of CSM patients were reported to have developmental cervical spine canal stenosis, while in the present study, all CSM patients had developmental cervical spine canal stenosis. Most scholars believe that the cervical spine canal stenosis is the underlying pathogenesis of CSM. Thus, in 1978, Hirabayashi ${ }^{4}$ proposed to use the posterior cervical expansive open-door laminoplasty to treat CSM. This surgery can directly relieve the compression to the dorsal spinal cord through removal of the proliferated yellow ligament or bony structures posterior to the spinal cord. It can also indirectly relieve the compression to the spine cord from anterior cervical disk, hyperplasic bone, and ossified posterior longitudinal ligament through expanding the spinal canal to cause the rear shift of the spinal cord, and ultimately achieve the purpose of relieving cervical spinal cord compression, improving spinal cord blood supply, and alleviating clinical symptoms. Many scholars have observed the expansion of cervical spinal canal and the rear shift of the spinal cord through research and believed that cervical spinal decompression can be successfully achieved in this surgery. ${ }^{5,6}$ However, there are some drawbacks in the traditional posterior cervical open-door laminoplasty. First, if there was poor preoperative cervical curvature, it would lead to a decrease in the tension that caused the rear shift of the spinal cord, which will affect spinal cord shift rate, thus affecting the effect of surgery. ${ }^{7}$ On the other hand, since no internal fixation was used, the incidence rate of poor postoperative cervical curvature was very high. ${ }^{8}{ }^{89}$ In addition, the "door-reclose-rate" was very high after the surgery, which led to spinal cord recompression and adversely impacted the long-term efficacy. ${ }^{10,11}$

In order to overcome the shortcomings of the surgery and to improve its efficacy, the traditional posterior cervical open-door laminoplasty was modified: on the basis of the traditional surgery, unilateral short-segmental mass screw or internal fixation and fusion with pedicle of vertebral arch nail-rod system. Briefly, the fixation range was from $\mathrm{C} 4-6$, the cervical lordosis was maintained with a prebent nail-rod system, short-segmental fusion was achieved through bone implantation in the lateral side of the door shaft, meanwhile, the opened vertebral lamina curtain of $\mathrm{C} 3-7$ was fixed to the nail-rod through large-size silk thread to maintain postoperative cervical curvature and to prevent postoperative "door reclose". The modified surgery was reported to achieve good clinical efficacy in many studies. ${ }^{12-14} \mathrm{~A}$ recent study that evaluated clinical efficacy with cervical JOA score showed that the improvement rate of JOA in modified surgery group was $44.5 \%$ and was significantly better than the conventional surgery group (JOA improvement rate was $32.6 \%$ ). However, there are few literatures regarding the long-term efficacy of the modified surgery. Du et a ${ }^{15}$ reported in a $\sim 10$-year follow-up study after CSM posterior decompression surgery that the postoperative JOA score in lateral mass screw internal fixation group was significantly better that of simple laminectomy and laminoplasty group, and the incidence of axial symptoms was also lower. A most recent study showed 
that a high preoperative JOA scale was associated with a good clinical outcome after laminoplasty. ${ }^{16}$

In this study, we followed up the cases who had modified surgery in our hospital for $>3$ years, with an average follow-up of 4.5 years, which has reached the scale of midor even long-term follow-up. We found that the clinical symptoms were improved significantly, the JOA score at follow-up was significantly better than the preoperative score, and JOA score improvement rate was as high as $80.27 \%$. There was no deterioration of neurological damage, and some even showed certain level of neurological function improvement. Although the incidence of C5 nerve palsy was reported to be high after posterior surgery $(4.8 \%-11 \%),{ }^{17,18}$ and there were also early $\mathrm{C} 5$ nerve palsy cases after surgery in this study, within a year after surgery, most cases were completely recovered, and there was no more C5 nerve palsy case at follow-up. The incidence rate of axial symptoms was not high either: the rate of neck and shoulder pain was $10.0 \%$, while it was reportedly $6 \%-60 \%$ in the literature. ${ }^{19,20}$ All the patients except three were satisfied with the surgery outcomes, in general, and the long-term clinical efficacy of the modified surgery was satisfactory.

Compared with the traditional surgery, in addition to the improved clinical efficacy, another advantage of the modified surgery is that cervical lordosis can be well maintained, and poor cervical sagittal sequence caused by peeling of neck muscles and opening of vertebral lamina was avoided. Through retrospective study, $\mathrm{Hu}$ et $\mathrm{al}^{19}$ found that the $D$-value of cervical lordosis was increased from $3.6 \pm 0.5 \mathrm{~mm}$ preoperatively to $9.1 \pm 0.7 \mathrm{~mm}$ postoperatively, and the difference was statistically significant. Miyamoto et al showed that, even in the presence of preoperative local kyphosis, the angle of C2-7 lordosis was also improved after surgery, while it was worsened after traditional surgery. ${ }^{14}$ In this study, after long-term follow-up, although the degree of cervical curvature was lost a little bit after surgery, but compared with that of preoperation, there was no significant difference. Cervical lordosis was well maintained, and there was no cervical kyphosis case.

There are still a lot of controversies regarding factors that affect the prognosis and symptom improvement rate. Age is a well-recognized influential factor, and older patients have a poorer prognosis. ${ }^{22,23}$ Sex was not an independent influential factor, ${ }^{23,24}$ which was also confirmed in the present study. Whether ISI on T2-weighted cervical spine MRI images is a prognostic factor is currently still controversial. Generally, it was thought that cervical spinal cord compression caused by cervical spine instability, increase in abnormal activity and osteophytes resulted from vertebral degeneration is the cause of ISI on T2-weighted images of spinal cord..$^{25,26}$ Shin et $\mathrm{al}^{27}$ proposed that preoperative ISI on T2-weighted images of spinal cord is an important factor affecting the prognosis; while Arvin et $\mathrm{al}^{28}$ found that patients whose postoperative ISI did not change also had low postoperative symptom remission rate; Rahmi et $\mathrm{al}^{29}$ also confirmed that the prognosis of patient with either pre- or postoperative ISI was poor. ${ }^{33} \mathrm{How}-$ ever, some scholars believe that the ISI change had nothing to do with prognosis. ${ }^{30}$ According to a recent meta-analysis study, ISI on T2-weighted images alone cannot effectively predict the prognosis, however, ISI on T2-weighted images plus low signal intensity on T1-weighted image, or ratio of ISI on T2-weighted images versus other normal signal intensity, or ratio of ISI on T2 versus signal intensity on T1 can be used as prognostic factors. ${ }^{31}$ In this study, preoperative ISI on T2-weighted cervical spine MRI images was found to be an independent risk factor affecting postoperative JOA score, but no comparison was made with that of T1-weighted images, so further study was needed to confirm that conclusion. Preoperative JOA score was also an independent factor affecting the postoperative JOA score, the worse preoperative spinal cord function, the less likely a full postoperative recovery. So most scholars have advocated an early surgical intervention, ${ }^{32}$ the longer the duration of the disease, the more severe spinal cord damage, and the possibility of recovery even after surgical decompression is also low. Curvature of the cervical spine, the number of spine segments with lesion, combination with OPLL, or the extent of cervical spinal canal stenosis was not an independent predictor affecting postoperative JOA score, which may indicate that there is no need to excessively pursue the degree of lordosis corrected, or the extent of the "door" opened when performing the surgery; otherwise, it will stretch the nerve roots, especially the $\mathrm{C} 5$ nerve root to cause the C5 nerve palsy.

Finally, regarding the safety of the lateral mass screw, it has been reported in many literatures that lateral mass screw surgery is simple with high safety rate. Recently, Kim et $\mathrm{al}^{33}$ conducted a large sample study, they summarized data of 1,256 lateral mass screws, all of which were manually implanted. The incidence rate of a screw implanted into the intervertebral foramen was $0.876 \%$ (mostly in C6), and the incidence rate of joint process injury was $1.433 \%$ (mostly in C3). In another study, analysis based on 325 cases and 1,662 lateral mass screws showed that there were 27 screws causing lateral vertebrate mass fractures, only three double cortical screws causing nerve damage, and three cases with loose screws that were pulled out. ${ }^{34}$ Overall, the 
incidence rate of complications related to internal fixation was low. In this study, after long-term follow-up, the location of all internal fixations was stable, there were no complications such as screw displacement, loose, pullout, or broken, and no occurrence of screw stimulating the nerve root. The experience we gained from this study is that the depth of the nail implantation was strictly limited to $1.4 \mathrm{~mm}$, and there is no necessary to have double cortex fixation unless there was presence of $\mathrm{C} 3$ or C7 instability. Bilateral C4-6 spines were routinely fixed so that the strength of the cervical spine internal fixation was ensured to not only maintain cervical lordosis but also avoid the risk of screw pullout after long-term fixation of C3 or C7 as well as the stiffness of the neck after long-term fixation. There was no wound infection, pneumonia, urinary tract infection, or anesthesia accidents reported for any patient. There was only one case of postoperative hematoma. The operation time can be controlled in $<3$ hours, and the amount of bleeding is limited. In general, the safety of the modified surgery is high, and the surgery is simple and feasible.

There are several limitations of this study. 1) This is a retrospective study and lacks control groups with other surgical approaches; however, the clinical efficacy of the modified open-door surgical approach reported in this study is superior to that of traditional open-door surgical approach.

2) The sample size is relatively small, and there were also cases lost during the follow-up, which might adversely affect the result. 3) The present study is a single-center study, and the results need to be further confirmed with multicenter prospective studies in the future.

\section{Conclusion}

It is safe to use posterior cervical open-door laminoplasty with unilateral short-segment mass screw fusion to treat patients with CSM. Our long-term follow-up study showed the treatment was effective, the neurological function improvement was significant, and the cervical lordosis was well maintained. Patient's age, preoperative JOA score, and preoperative ISI were the statistically significant independent factors that affected the postoperative JOA score. Based on the results of this study, we recommend that, if evidence of spinal cord injury is found in CSM patients, such modified surgery should be performed as soon as possible in order to achieve the best surgical outcomes.

\section{Acknowledgment}

The study was funded by the Capital Health Development Special Scientific Research Projects (2014-2-2023), Beijing, People's Republic of China.

\section{Disclosure}

The authors report no conflicts of interest in this work.

\section{References}

1. Furlan JC, Kalsi-Ryan S, Kailaya-Vasan A, Massicotte EM, Fehlings MG. Functional and clinical outcomes following surgical treatment in patients with cervical spondylotic myelopathy: a prospective study of 81 cases. J Neurosurg Spine. 2011;14(3):348-355.

2. Kaptain GJ, Simmons NE, Replogle RE, Pobereskin L. Incidence and outcome of kyphotic deformity following laminectomy for cervical spondylotic myelopathy. J Neurosurg. 2000;93(2 suppl): 199-204.

3. Zhang JT, Wang LF, Liu YJ, et al. Relationship between developmental canal stenosis and surgical results of anterior decompression and fusion in patients with cervical spondylotic myelopathy. BMC Musculoskelet Disord. 2015;16:267.

4. Hirabayashi K. Expansive open-door laminoplasty for cervical spondylotic myelopathy. Japan J Surg. 1978;32:5.

5. Shiozaki T, Otsuka H, Nakata Y, et al. Spinal cord shift on magnetic resonance imaging at 24 hours after cervical laminoplasty. Spine (Phila Pa 1976). 2009;34(3):274-279.

6. Zhu JC, Liu XG, Liu ZJ, et al. Correlation between cervical curvature and spinal cord shift, surgical outcome after expansive open-door laminoplasty. Chin J Spine Spinal Cord. 2013;23:7.

7. Suda K, Abumi K, Ito M, Shono Y, Kaneda K, Fujiya M. Local kyphosis reduces surgical outcomes of expansive open-door laminoplasty for cervical spondylotic myelopathy. Spine (Phila Pa 1976). 2003;28(12): $1258-1262$.

8. Kawaguchi Y, Kanamori M, Ishihara H, Ohmori K, Nakamura H, Kimura T. Minimum 10-year followup after en bloc cervical laminoplasty. Clin Orthop Relat Res. 2003;411:129-139.

9. Sakaura H, Hosono N, Mukai Y, Iwasaki M, Yoshikawa H. Medium-term outcomes of C3-6 laminoplasty for cervical myelopathy: a prospective study with a minimum 5-year follow-up. Eur Spine J. 2011; 20(6):928-933.

10. Matsumoto M, Watanabe K, Hosogane N, et al. Impact of lamina closure on long-term outcomes of open-door laminoplasty in patients with cervical myelopathy: minimum 5-year follow-up study. Spine (Phila Pa 1976). 2012;37(15):1288-1291.

11. Lee DH, Park SA, Kim NH, et al. Laminar closure after classic Hirabayashi open-door laminoplasty. Spine (Phila Pa 1976). 2011;36(25): E1634-E1640.

12. Kristof RA, Kiefer T, Thudium M, et al. Comparison of ventral corpectomy and plate-screw-instrumented fusion with dorsal laminectomy and rod-screw-instrumented fusion for treatment of at least two vertebrallevel spondylotic cervical myelopathy. Eur Spine J. 2009;18(12): 1951-1956.

13. Zhang QM, Shen HL, Wang JY. Clinical studies of modified open door laminoplasty for spondylotic myelopathy. J Capital Med Univ. 2008;29:4.

14. Miyamoto H, Maeno K, Uno K, Kakutani K, Nishida K, Sumi M. Outcomes of surgical intervention for cervical spondylotic myelopathy accompanying local kyphosis (comparison between laminoplasty alone and posterior reconstruction surgery using the screw-rod system). Eur Spine J. 2014;23(2):341-346.

15. Du W, Wang L, Shen Y, Zhang Y, Ding W, Ren L. Long-term impacts of different posterior operations on curvature, neurological recovery and axial symptoms for multilevel cervical degenerative myelopathy. Eur Spine J. 2013;22(7):1594-1602.

16. Shin JW, Jin SW, Kim SH, et al. Predictors of outcome in patients with cervical spondylotic myelopathy undergoing unilateral open-door laminoplasty. Korean J Spine. 2015;12(4):261-266.

17. Nassr A, Eck JC, Ponnappan RK, Zanoun RR, Donaldson WF 3rd, Kang JD. The incidence of C5 palsy after multilevel cervical decompression procedures: a review of 750 consecutive cases. Spine (Phila Pa 1976). 2012;37(3):174-178. 
18. Nakashima H, Imagama S, Yukawa $\mathrm{Y}$, et al. Multivariate analysis of C-5 palsy incidence after cervical posterior fusion with instrumentation. J Neurosurg Spine. 2012;17(2):103-110.

19. Sani S, Ratliff JK, Cooper PR. A critical review of cervical laminoplasty. Neurosurgery. 2004;14:12.

20. Wang M, Luo XJ, Deng QX, Li JH, Wang N. Prevalence of axial symptoms after posterior cervical decompression: a meta-analysis. Eur Spine J. 2016;25(7):2302-2310.

21. Hu ZH, Li NN, Sun HZ, Liu XB, Xu XT. Multi-segmental cervical ossification of posterior longitudinal ligament treated by posterior decompression and internal fixation of cervical lateral mass screw. J Clin Rehabil Tissue Eng Res. 2011;15:3.

22. Yamazaki T, Yanaka K, Sato H, Uemura K, Tsukada A, Nose T. Cervical spondylotic myelopathy: surgical results and factors affecting outcome with special reference to age differences. Neurosurgery. 2003; 52(1):122-126; discussion 126.

23. Koc RK, Tucer B, Menku A. Prognostic factors in cervical spondylotic myelopathy: a clinical prospective study. Neurosurgery. 2015;1:7.

24. Yagi M, Ninomiya K, Kihara M, Horiuchi Y. Long-term surgical outcome and risk factors in patients with cervical myelopathy and a change in signal intensity of intramedullary spinal cord on Magnetic Resonance imaging. J Neurosurg Spine. 2010;12(1):59-65.

25. Mattei TA, Goulart CR, Milano JB, Dutra LP, Fasset DR. Cervical spondylotic myelopathy: pathophysiology, diagnosis, and surgical techniques. ISRN Neurol. 2011;2011:463729.

26. Zhang L, Zeitoun D, Rangel A, Lazennec JY, Catonne Y, PascalMoussellard H. Preoperative evaluation of the cervical spondylotic myelopathy with flexion-extension magnetic resonance imaging: about a prospective study of fifty patients. Spine (Phila Pa 1976). 2011;36(17): E1134-E1139.
27. Shin JJ, Jin BH, Kim KS, Cho YE, Cho WH. Intramedullary high signal intensity and neurological status as prognostic factors in cervical spondylotic myelopathy. Acta Neurochir (Wien). 2010;152(10):1687-1694.

28. Arvin B, Kalsi-Ryan S, Karpova A, et al. Postoperative magnetic resonance imaging can predict neurological recovery after surgery for cervical spondylotic myelopathy: a prospective study with blinded assessments. Neurosurgery. 2011;69(2):362-368.

29. Rahmi K, Bulent Tucer, Ahmet Menku, et al. Prognostic Factors in Cervical Spondylotic Myelopathy: A Clinical Prospective Study. Neurosurgery. 2015;1:34-40.

30. Morio Y, Teshima R, Nagashima H, Nawata K, Yamasaki D, Nanjo Y. Correlation between operative outcomes of cervical compression myelopathy and MRI of the spinal cord. Spine (Phila Pa 1976). 2001;26(11):1238-1245.

31. Tetreault LA, Dettori JR, Wilson JR, et al. Systematic review of magnetic resonance imaging characteristics that affect treatment decision making and predict clinical outcome in patients with cervical spondylotic myelopathy. Spine (Phila Pa 1976). 2013;38(22 suppl 1): S89-S110.

32. Yoon ST, Raich A, Hashimoto RE, etal. Predictive factors affecting outcome after cervical laminoplasty. Spine (Phila Pa 1976). 2013;38(22 suppl 1): S232-S252.

33. Kim HS, Suk KS, Moon SH, et al. Safety evaluation of freehand lateral mass screw fixation in the subaxial cervical spine: evaluation of 1256 screws. Spine (Phila Pa 1976). 2015;40(1):2-5.

34. Katonis P, Papadakis SA, Galanakos S, et al. Lateral mass screw complications: analysis of 1662 screws. J Spinal Disord Tech. 2011;24(7) 415-420.
Therapeutics and Clinical Risk Management

\section{Publish your work in this journal}

Therapeutics and Clinical Risk Management is an international, peerreviewed journal of clinical therapeutics and risk management, focusing on concise rapid reporting of clinical studies in all therapeutic areas, outcomes, safety, and programs for the effective, safe, and sustained use of medicines. This journal is indexed on PubMed Central, CAS,

\section{Dovepress}

EMBase, Scopus and the Elsevier Bibliographic databases. The manuscript management system is completely online and includes a very quick and fair peer-review system, which is all easy to use. Visit http://www.dovepress.com/testimonials.php to read real quotes from published authors. 